\title{
Not Yet
}

\section{The Philosophical Significance of Aesthetics ${ }^{1}$}

\section{Christoph Menke}

\begin{abstract}
AвSTRACт The paper asks for the preconditions and the consequences of the emergence of aesthetics in and for philosophy. The question is: what does it mean for philosophy to engage the question of the aesthetic? My answer will be: it means nothing less than putting philosophy in question. Or, more precisely: by engaging the question of the aesthetic, philosophy puts itself in question. In order to show this, I will refer to a brief passage in the Phenomenology of the Spirit and then attempt to turn it against what I take it to be Hegel's own intention. The paper attempts to sketch this argument in three brisk moves by (1) distinguishing a philosophy of the "poetic" from a philosophy of the "aesthetic"; (2) describing the aesthetic as "regressive" and "(self-)reflexive"; and (3) sketching the paradoxical place of aesthetics within philosophy.

KEYWORDS The aesthetic, the poetic, Aristotle, Hegel, aesthetics within philosophy
\end{abstract}

In this paper I want to ask for the preconditions of the emergence of aesthetics in philosophy and for the consequences that this emergence of aesthetics had for philosophy. The question is: what does it mean for philosophy to engage the question of the "aesthetic"? My answer will be: it means nothing less than putting philosophy in question. Or, more precisely: by engaging the question of the aesthetic, philosophy puts itself in question.

In order to show this, I proceed in three brisk moves. (1) I will distinguish a philosophy of the aesthetic from a philosophy of the poetic, or aesthetics from poetics; (2) I will describe the aesthetic as regressive and reflexive; (3) I will sketch the paradoxical place of aesthetics within philosophy.

\section{1}

According to Aristotle's definition, "poetics" is the name of an investigation that concerns "[p]oetry, its essence and its several species, with the characteristic function of each species and the way in which plots must be constructed if the poem is to be a success." ${ }^{2}$ Aristotle understood this as the philosophical investigation of a mode of representation and experience that is itself (almost) already philosophical. The well-known distinction offered in Book 9 of the Poetics between poetry and history is this:

the difference between a historian and a poet is not that one writes in prose and the other in verse [...] The real difference is this, that one tells what happened 
and the other what might happen. For this reason poetry is something more scientific [philosophôteron, more philosophical] and serious than history, because poetry tends to give general truths while history gives particular facts. (Poetics, $\left.145^{1} \mathrm{a}-\mathrm{b}\right)$

The modes of representation seem to be capable of being ordered along a scale that extends from the particular to the universal, from the representation of an event to the representation of a form. History and philosophy constitute the extremes of this scale. Poetry lies between them; it is not (or no longer) concerned with what a particular human being really did, but (already) with what "a certain type of man will do or say either probably or necessarily."3 Understood correctly, then, the comparative placement of historiography and poetry Aristotle offers according to their respective distance from or proximity to philosophy does not assign a firm location to poetry, let alone one halfway between history and philosophy. Rather, the comparative degree of the adjective - "more philosophical" - indicates a progression, an approximation of poetry to philosophy. Poetry is "more philosophical" than history because it is in motion, on its way from the one to the other, away from the representation of the merely particular toward that of the universal, toward philosophy. Poetry can be addressed as something "more philosophical" than historiography because the becoming of philosophy begins with poetry.

Aristotle also writes in the Metaphysics à propos of his elucidation of what it means that philosophy begins with wonder, that the "lover of myths," of tales and narratives (philómuthos), is already "in a sense a philosopher." This view is confirmed from the side of poetry, when the chorus in Sophocles' King Oedipus, as the observer of the hero's history, at the end of the tragedy commences a process of contemplation, of reflection on the events, that will lead to an insight into the form of human happiness and into its dependence on fate:

С ноRUs. Dwellers in our native land of Thebes, see to what a storm of cruel disaster has come Oedipus here, who knew the answer to the famous riddle and was a mighty man, on whose fortune every one among the citizens used to look with envy! So that one should wait to see the final day and should call none among mortals fortunate, till he has crossed the bourne of life without suffering grief. ${ }^{5}$

This insight that the tragic chorus articulates and which Aristotle will reframe as a philosophical insight (and discuss critically) in Book 1 of the Nicomachean Ethics ${ }^{6}$ is a universal insight. Here, at the end of the 
tragic poem, still within the poem or on its margin, a consideration begins which will transform the perception and sensation whose object is the particular fate, the fate of this one human being and the event of his tragic downfall, into an insight into the fate of the human being as such. With this insight, poetry transitions into philosophy; the end of poetry is the beginning of philosophy.

This proposition, which marks the destination of Aristotle's Poetics, is taken up by Hegel, who reads it from its end, that is to say, backwards: if the end of poetry is the beginning of philosophy - as Sophocles' tragedy shows and Aristotle's Poetics states - then the beginning of philosophy is the end of poetry. This Hegelian inversion does not dispute the original meaning of the proposition; to the contrary, it presupposes it. For Hegel, too, poetry is "more philosophical" than (ordinary) historiography. But poetry's being "more philosophical" than history is not tantamount to its being philosophy. Hegel writes in the Phenomenology of the Spirit:

Just as it is essential for the statue to be the work of human hands, so is the actor essential to his mask - not as an external condition from which artistically considered [in der Kunstbetrachtung] we must abstract; or, so far as we do have to make abstraction from it, we admit just this, that Art does not yet contain in it the true and proper self. ${ }^{8}$

If "containing" and unfolding "the true and proper self" can be regarded as one definition of philosophy, then art and its "consideration" stand, according to Hegel, under the law of not yet being - and of being incapable of ever becoming - philosophy. The claim that art, in contrast with philosophy, "does not yet contain in it the true and proper self" has a double meaning: art is the representation of an act that does not yet fully comprehend itself, that is to say, the representation of an act that is not yet in the full sense conscious of itself; ${ }^{9}$ and - which is to say, because - art is itself an act, an act of representing, that does not yet fully comprehend itself, that is not yet in the full sense conscious of itself. Art, in contrast with philosophy, "does not yet contain in it the true and proper self" because its representation, and hence also that which is represented in it, is not yet fully comprehended.

The shift from Aristotle's to Hegel's definition of the relation between poetry and philosophy, a shift Hegel enacts, following Aristotle, on the example of tragedy - one from "almost already" to "not yet," from poetry as the beginning of philosophy to philosophy as the end of poetry - is both slight, a mere shift of accent, and momentous. For this shift expresses precisely the new transformed understanding of poetry or art 
that is terminologically indicated by the invention of the concept of the "aesthetic."10 Only a poetic notion of poetry can seek to recognize in it the beginning of philosophy. Understanding poetry poetically means tracing it back to an insight and to an act that are (almost) already philosophical: because poetic insight, just like philosophical insight, regards not any particular event but its universal form, and because the act of poetic representation, the concatenation of events into a fable, is - thus Aristotle's definition of "mimesis" - the imitation of this universal form. When Hegel, by contrast, defines art on the basis of its relating to philosophy as a "not yet," he no longer understands it poetically, basing his argument instead on its new "aesthetic" definition. For the aesthetic, not only, is not the philosophical, which is to say, something other than the philosophical; for so is the poetic. The aesthetic, rather, is "not yet" the philosophical because it means a kind or dimension of experience, and a kind of dimension of representation that remains before or beneath any transparent self-consciousness. That art, unlike philosophy, does not yet "contain in it the true and proper self" means that art is something that has fallen behind - something below the true self. And this is precisely what it means to understand art "aesthetically."

\section{2}

Hegel's definition of art under the sign of "not yet" describes art by virtue of an essential deficiency: it does not yet "contain in it the true and proper self." In this, Hegel's definition of art is an "aesthetic" one in the specific, i.e. specifically modern sense of that term. Hegel's definition of art is specifically aesthetic moreover in that it defines this aesthetic deficiency - the deficiency that is the aesthetic - as a deficiency of knowledge, or to be precise, of knowledge of itself, as a deficiency of self-consciousness: while the "higher language" of art does not have "the unconscious naturalness and naivety [...] [of] the language accompanying ordinary actions in real life;" while the "higher language" of art is thus, also according to Hegel, conscious, artificial, and sentimental or reflexive; art remains at the same time incapable of "know[ing]" and "assert[ing]" its own act of making - the making of the statue by human hands, the making of the heroes by the actor. ${ }^{11}$ Art essentially eludes itself: its act of making or doing is not an object of its knowing or a content of its saying.

By describing art through a severance between doing and knowing, Hegel indicates precisely its newly gained aesthetic definition. Yet Hegel simultaneously misunderstands this aesthetic divergence by describing it as the knowledge of art falling behind its doing. Aesthetically, the in- 
verse is true: the doing of art falls behind, it escapes its knowing. The deficiency of knowledge that is characteristic of art is not exterior to its doing but rather defines the doing of art as an aesthetic doing. In overcoming this deficiency, that is to say, in gaining consciousness of its doing, art would thus precipitate its own disappearance. The knowledge of art's doing would not be a knowledge of art's doing. The doing that we can know because it is a doing by force of "the true and proper self" - a doing that is an expression of knowledge (on the part of the self that does) and can thus become an object of knowledge (on the part of the observing self)- this knowable, because self-conscious, doing is not art's doing. The doing of art is not a knowable doing because it is not selfconscious. This is the positive, and that is to say: the aesthetic version of Hegel's negative proposition regarding art: that art does not know of its doing means that the doing of art is not an object of knowing because it is not grounded in knowing. Art's doing eludes knowledge.

Philosophical aesthetics is the theory of such a doing: the theory of a doing that is not an expression nor an object of knowledge; a doing before and beyond all knowledge. ${ }^{12}$ This doing, whose theory is philosophical aesthetics, engages images and representations (in the wide sense of both words) productively and receptively, engendering and apprehending them; the subject matter of aesthetics is the making of images and representations. Because it eludes knowledge, philosophical aesthetics calls this making "dark" (Baumgarten): it is not a clear and selfconscious but an "unconscious" doing (Herder). Aesthetics says of this dark doing not only that it is "stronger" than the clear or self-conscious one (whence Baumgarten calls philosophical aesthetics also by the name of "emphaseologia"). It says of this dark doing also that it constitutes the "ground" (of the soul: fundus animae) that is presupposed by and at the same time replaced by the higher, self-conscious operations of the subject. Insofar as art "contains" (Hegel) its doing as a dark one, the soul experiences through art its own ground.

Aesthetics understands this also in the sense of a regression: the aesthetic is the medium of a return into the aboriginally dark making of images at the beginning of the soul's activity. Yet that art, aesthetically understood, is a return into the ground (of the soul) must be understood not solely as a regression, but also as a reflection: the aesthetic, as a regression into the ground, is the medium of a particular form of self-reflection. "Aesthetic" is thus not merely the name for a different, a "dark" mode of making representations, one which - thus Baumgarten - stands in "analogy" to the "clear" one. "Aesthetic," rather, is the name 
for an altogether different kind of regarding and performing the making of representations; a kind of performing, moreover, that transforms the non-aesthetic making of representations by its self-reflection: the aesthetic kind of regarding and performing transmutes the clear and selfconscious act of representing into a dark and unconscious one by discovering and unfolding underneath, or indeed within the act, and that is to say, in any act, of representing - of a representation whose ground seems to be the "true and proper" subject, conscious of itself - its "dark ground." "Aesthetic" thus means, and decidedly so since Herder's critical transformation of Baumgarten's project, a genealogical form of reflection: a form of reflection that unfolds within the clear, and hence against the clear, its own dark ground. That is why the aesthetic-genealogical reflection can at the same time exist only as an aesthetic practice: the dark ground is not a potential object of knowledge, but rather becomes apparent only in a performance - in a different performance of the act of representing. Aesthetic representation exists only as an aestheticization of the act of representing: as an aesthetic transformation of representation such that the latter's dark ground becomes apparent.

Thus, the decisive difference between the poetic and the aesthetic, between art considered as almost already philosophical and as not yet philosophical, emerges. Following Wolfgang Iser, one can describe the step from a poetic to an aesthetic notion of art as an "interiorization of possibility."13 - Poetry, poetically understood, is the realization of a preexisting possibility: the poem consists in a composition of events that imitates an action that, while not having taken place in reality, is possible. "Possible" means in this context: in accordance with those trajectories of action that are (for us) probable or even necessary. In the poetic composition of events, those possibilities become apparent which we, without quite becoming aware of the fact, actualize in our lives; poetry makes explicit, and thus displays, probable possibilities of life. - With the aesthetic understanding of art, by contrast, possibility seems to have "emigrated out of Nature [or out of "life"14] and into the artist's mind;"15 for art, aesthetically understood, is not an imitation of that which is probable in the life-world but rather an exploration of "forms of perceptibility" and representability, of the "plenum" of possibilities ${ }^{16}$ - but of the possibilities not of life, imitated by art, but of representation itself. Art, aesthetically understood, unfolds the play of the imagination as a

process of gaining and simultaneously of playing down the gains. It [sc. the aesthetic play of "force" or "difference"] thus becomes not only variable but, in 
principle, also serial. Serial variability $[. .$.$] would then be one characteristic of$ the aesthetic. What is concealed here could be illuminated by a sentence from Borges: "that imminence of a revelation that is not yet produced is, perhaps, the aesthetic reality."17

The aesthetic interiorization of the possible described by Iser must not be taken to be a subjectivization in any established sense of that term. And this also means, conversely, that if aesthetics speaks of the "subject" (and indeed, philosophical aesthetics is the first one to do so in the modern sense of the word: it does so in the chapter of Baumgarten's Metaphysics where, in a single move, the legitimacy of dark representations is posited against the privilege of clear ones and the soul is addressed as the "subject," that is, as ground) it does so in order to relate representations back to possibilities, to potentiality, and thus to think representations not as something that occurs but rather as something that is made or produced. Yet the possibilities that produce representations, aesthetically understood, are at the same time not the "property" of a subject of which the latter knows and over which it freely disposes. The aesthetic subject does not have possibilities, it is possibility: "anima mea est vis" (Baumgarten). To put it another way, the meaning of "possibility" fundamentally changes in the process of its aesthetic interiorization. Understood poetically, that is to say, on Aristotle's terms, possibility is related to universality, to the universality of a form. Possibility is the ability to actualize a universal form (and thus to render it concrete and specific). To have an ability means to be able to do something, and hence, to be able to bring something to success. A subject with abilities is a master; "possibility," poetically understood, is mastery. The aesthetic possible, by contrast, is paradoxical: a "process of gaining and simultaneously of playing down the gains" (Iser); that is to say, ability and inability at once.

To offer a terminological frame for this distinction: the aesthetic possible is not an ability but a force. A force, too, is productive, but while the realization of an ability is an instance of success or accomplishment, a force produces a mere effect. Subjective abilities are the possibility of successful conjunctions of the universal and the particular, of universal form and particular case; aesthetic forces are the possibility of effective conjunctions of particulars with each other, of this and that event. Abilities realize themselves in action, that is to say, in the constitutively teleological act of doing what is good. Forces unfold in play, ${ }^{18}$ that is to say, in the serial connection and disconnection and reconnection and again disconnection of events. The poetic subject (which is not yet called 
"subject") is thus like the practical one: it realizes in an example, and thus also in an exemplary manner, the possible universal. The aesthetic subject (which is now called "subject," but is precisely not a subject in the common philosophical sense) unfolds the play of forces, and is thus no longer - or rather, with Hegel, not yet - practical. It does not know itself, and so is incapable of anything; again and again, it dissolves what it has - equally without intention - constructed.

\section{3}

When Hegel claims "that Art does not yet contain in it the true and proper self," he states the constitutive, i.e., insuperable behind-ness of the aesthetic vis-à-vis the philosophical. I have suggested that this claim is borne out once we understand the aesthetic as the medium of an unfolding of "forces" (in distinction to "abilities") that is prior to (or: not yet) self-consciousness. At the same time, Hegel insists on the reflexive, even self-reflexive character of the aesthetic. In Hegel's view, at least the view advocated in the Phenomenology of the Spirit (which is the closest Hegel ever came to contemporary early Romanticism), the aesthetic contains not yet the "true and proper self" but already a form of self-reflection. For in the chapter on "Religion in the Form of Art," Hegel not only insists on the difference between "cult" and art by claiming that whereas "cult" is "actual practice," all art is "Vorstellung" - imagination or, more accurately, presentation, performance..$^{19}$ Hegel also, closely following Schiller and Friedrich Schlegel, draws a distinction between two forms of art, of artistic presentation: the first or "earliest language" (erste Sprache) ${ }^{20}$ of epic art and the later and "higher language" (höhere Sprache) of tragedy. ${ }^{21}$ Hegel writes on epic art:

The Minstrel [of the epic song] is the individual and actual Spirit from whom, as a subject of this world, it [the world] is produced and by whom it is borne. His "pathos" is not the stupefying power of Nature [a critique of Plato's account of poetry as being produced out of "inspiration and possession"] but Mnemosyne, recollection and a gradually developed inwardness, the remembrance of essence that formerly [in cult] was directly [immediately] present. He is the organ that vanishes in its content; what counts is not his own self but his Muse, his universal song. ${ }^{22}$

The earliest language of epic art is defined by the erasure of the fact of its own presentation. It is as though its content presented itself. The language of epic art is defined as neutral representation of "a reality, which, in content and in manner of presentation, is complete in itself and re- 
mote from the narrator as an individual."23 By contrast, Hegel speaks of tragedy as a "higher language" because it does not retreat behind the objectivity of its content, but emerges in its genuine poetic character, as the act of speaking:

In regard to form, the language ceases to be narrative because it enters into the content, just as the content ceases to be one that is imaginatively presented. The hero is himself the speaker. ${ }^{24}$

Indeed, the characters of tragedy are themselves "artists" - artists of themselves -, for they are presented in tragedy as actively presenting (themselves). Epic representation is replaced by the self-reflexive awareness of the performative process of its creation. Hegel defines the "higher language" of tragedy in exactly the same way in which Friedrich Schlegel had spoken of a poetry that, "by analogy to philosophical terminology[,] must be called transcendental poetry" because it is "critical" and "presents its producing along with its product." It is "always [...] simultaneously poetry and the poetry of poetry," which "presents itself along with each of its presentations." 25

Hegel's (as one might say: "Romantic") insistence on the self-reflexive structure of the aesthetic form of art is crucial for an adequate understanding of the way in which aesthetics contrasts the serial variability of the play of forces with the successful actualization of practical abilities. For it would be a severe misunderstanding to take this to be just another inversion of Platonism. Plato's reservation regarding poets (the reservation which Aristotle's remark that the "myth-lover" is also "in a certain sense a philosopher" intended to reject) was this:

For all the good epic poets utter all those fine poems not from art, but as inspired and possessed, and the good lyric poets likewise; just as the Corybantian worshippers do not dance when in their senses, so the lyric poets do not indite those fine songs in their senses, but when they have started on the melody and rhythm they begin to be frantic, and it is under possession - as the bacchants are possessed [...] - that the soul of the lyric poets does the same thing, by their own report. ${ }^{26}$

Poetry - thus Gadamer's précis of the Platonic view - is "divine mania and possession," and thus "in any case [...] no knowledge, no ability that were able to give an account of itself and its truth." ${ }^{27}$ Poetry is not a practical performance, not an act; its ground is not a practical knowledge, not an ability; the poem, hence, not a practical work, not a "good thing" - thus the series (and unity) of the Platonic objections. Does the aesthetic 
definition of art - the question would seem inevitable - not just repeat these dual oppositions? Is what Plato calls art's "obsession" and its unconscious speech not the same as what aesthetics call "dark," its ground and play of forces - the only difference being that aesthetics invert the valuations that accompany an identical description?

Yet to read philosophical aesthetics as an inverse Platonism means to miss the decisive trait highlighted by Hegel's distinction between the "earliest language" of epic and the "higher language" of tragedy and indeed of all art that has become "aesthetic": it ignores the fact that the aesthetic is itself reflexive. Socrates describes the poet not as one who speaks from his own knowledge, "by art," but as one who is driven "by divine influence (dynamis)"; the poets are "merely the interpreters of the gods." ${ }^{28}$ What speaks through the poet is exterior to him, precedes him; the poet - thus the young Nietzsche approvingly quotes this Socratic image - "sounds forth from the abyss of being." 29 By contrast, the "dark ground," that is, the abyss of which aesthetics speaks, is located within the poet; and moreover, paradoxically, it is located precisely where he has rational abilities whose self-conscious employment constitutes the poet, insofar as he is also a master, a practical subject. The artistic act, aesthetically understood, consists not in unconsciously passing on the whisperings of the muses but in transmuting one's own self-conscious abilities (back) into unconscious forces. This transmutation of abilities into forces, of act into play is the aesthetic. The aesthetic, then, is not the reverse instead of the obverse - the play of forces instead of the realization of an ability. The aesthetic is the reverse of, and hence with, the obverse. The play of forces, aesthetically understood, is the underground or abyss within the realization of abilities. The aesthetic play of forces that emerges by transmutation from the realization of practical abilities thus always remains related back to the realization of practical abilities. By this very token, the aesthetic is constitutively reflexive: it exists only in its emergence from the practical which it is not. Understood in Platonic terms, poetry is the other of a practice founded on knowledge and mastery; aesthetically understood, poetry unfolds the other within the practice founded on knowledge and mastery.

In closing, I would like to return to the relationship between art (in the aesthetic sense) and philosophy. The hypothesis I would like to advocate runs as follows: if one understands, with Hegel, the aesthetic as in itself reflexive, or as self-reflexive, then the relationship between art and philosophy attains a structure different from the teleological one that Hegel's "not yet" indicates. If Hegel is right in understanding aesthetic 
art as a form of reflection, and if I am right in understanding the selfreflection of aesthetic art as a regression from ability to force, then there is no common standard by which to measure art and philosophy alike in order to judge that art is "not yet" on a par with the achievements of philosophy. Rather, if art is aesthetic precisely by being self-reflexive (and vice versa), the relationship between art and philosophy is a relationship of infinite strife.

Plato was able to promise a resolution of the strife between philosophy and poetry - which already he called "old" - because he construed this strife as the external opposition between mastery and enthusiasm, between one's own practical ability and divine power. For if practical mastery and poetic enthusiasm operate separately, then they can be severed as well. The antagonistic conjunction of abilities and forces, by contrast, renders the dispute between philosophy and poetry or art irresolvable. This irresolvable dispute between philosophy and art takes place within philosophy itself; its site is aesthetics. By defining the aesthetic as a reflexive transformation of practice, as a re-transmutation of its abilities into forces, aesthetics thus carries philosophy's dispute with art into philosophy such that the latter, philosophy, is no longer capable of resolving it.

The new dispute between philosophy and art, the one whose site is aesthetics, is a consequence of the fact that both sides are simultaneously antagonists and conjoined. ${ }^{30}$ The "old" dispute between philosophy and poetry of which Plato speaks and which he promises to end was one over the ground and the medium of practical wisdom: does wisdom originate in poetic enthusiasm or in rational thought? Aesthetics, by contrast, is the dispute of two modes of reflection. The aesthetic is a mode of reflection on practice, but then so is philosophy. Both modes of reflection engage the same object: they are reflections on practice, and primarily: on the practice of comprehension and representation. In their reflections, they develop contrasting images of this practice. The image created by philosophical reflection is one of a correspondence between mastery and success: philosophy intends to explain that we can have true knowledge, that we can offer convincing arguments, that we can make just decisions, that we can form good intentions. Philosophy makes this comprehensible by examining our abilities. For to have and to realize abilities means to bring something to success. The aesthetic creates a contrasting image of practice by inciting in us - as Friedrich Schlegel put it, speaking of Socratic irony - "a feeling of indissoluble antagonism between the absolute [das Unbedingte] and the relative [das 
Bedingte]." ${ }^{11}$ In the aesthetic performance, the practical correspondence of abilities and success is shattered in the antagonism between the play of forces and their uncontrolled effects.

As aesthetics unfolds their dispute, these two contrasting modes of reflection, the philosophical and the aesthetic one, are tied by a simultaneous double, and moreover doubly asymmetrical, conjunction. For aesthetics renders the aesthetic an object of philosophical reflection: aesthetics is a philosophical reflection on the aesthetic reflection - a philosophical reflection that seeks to prove for the aesthetic exactly the correspondence of ability and success that constitutes its definition of practice. Yet as the aesthetic itself is constitutively reflexive, it does not remain a mere object upon or on which philosophy reflects. As the aesthetic itself is the medium of an autochthonous and idiosyncratic reflection that engages in turn that practice of the philosophical reflection which engages it, the aesthetic, the latter, the aesthetic as an object, is simultaneously an opposite, and indeed an opponent and antagonist of the philosophical reflection. With the turn of the philosophical reflection toward the aesthetic - with the turn, that is, that defines aesthetics - philosophy thus turns toward something that turns back against it, against philosophy. When philosophy began to think the aesthetic as a reflexive performance, it consigned itself to a dispute that it can no longer decide in favor of either of the two sides.

\section{Notes}

1. Translated by Gerrit Jackson.

2. Aristotle, Poetics, trans. W. H. Fyfe (Cambridge, MA: Harvard UP, and London: Heinemann, 1932), 1447a.

3. Ibid.

4. Aristotle, Metaphysics, trans. Hugh Tredennick (Cambridge, MA: Harvard UP, and London: Heinemann, 1933/1989), 1.982b.

5. Sophocles, Oedipus Tyannus, in Ajax. Electra. Oedipus Tyrannus, trans. Hugh Lloyd-Jones (Cambridge, MA and London: Harvard UP, 1994), v. 1524-1530.

6. Aristotle, Nicomachean Ethics, trans. H. Rackham (Cambridge, MA and London: Harvard UP, 1934), 110ob.

7. "Therefore the primary requirement for a dramatic poet as an author is that he shall have a full insight into the inner and universal element lying at the root of the aims, struggles, and fates of human beings. He must be fully aware of the oppositions and complications to which action may lead in the nature of the case, whether these arise from subjective passion and individuality of character, 
or from human schemes and decisions, or from concrete external affairs and circumstances. And at the same time he must be capable of recognizing what those powers are which apportion to man the destiny due to him as a result of what he has done. The right as well as the aberration of the passions that rage in the human heart and impel to action must be equally clear to the dramatist, so that where to the ordinary man's eye it is obscurity, chance, and confusion that prevail, there is clearly revealed to him the actual accomplishment of what is absolutely rational and true." (Georg Wilhelm Friedrich Hegel, Aesthetics: Lectures on Fine Art, vol. 2, trans. T. M. Knox [Oxford: Clarendon Press, 1975], 1663.)

8. Georg Wilhelm Friedrich Hegel, Phenomenology of Spirit, trans. A. V. Miller, ed. J. N. Findlay (Oxford etc.: Oxford UP, 1977), 444.

9. Hegel refers to the speech act of the tragic hero that he describes as structurally not yet fully self-conscious. In this perspective, Oedipus exhibits the internal split between action and knowledge that defines any tragic speech act.

10. On the juxtaposition of a poetic and an aesthetic conception of art see Jacques Rancière, Le Partage du Sensible: Esthétique et Politique (Paris: La Fabrique-éditions, 2000), $28 \mathrm{ff}$.

11. Hegel, Phenomenology, 443-4.

12. In the following, I summarize an argument that I have developed in my Kraft: Ein Grundbegriff ästhetischer Anthropologie (Frankfurt am Main: Suhrkamp, 2008), chaps. 3-4.

13. Wolfgang Iser, The Fictive and the Imaginary: Charting Literary Anthropology (Baltimore and London: Johns Hopkins UP, 1993), chaps. IV.5, VI.1.

14. Poetics, 1450 .

15. Ibid. 285 f.

16. Ibid., 235.

17. Wolfgang Iser, Das Fiktive und das Imaginäre: Perspektiven literarischer Anthropologie (Frankfurt am Main: Suhrkamp, 1991), 409 (the passage is absent from the existing English translation: The Fictive and the Imaginary: Charting Literary Anthropology (Baltimore: Johns Hopkins UP, 1993). - For the quotation from Borges cf. J.L. Borges, "The Wall and the Books" (1950), Other Inquisitions: 1937-1952, trans. Ruth Simms (New York: Simon and Schuster, 1965), 5.

18. The aesthetic concept of play is rooted in that of force - not that of freedom.

19. Hegel, Phenomenology, $\$ 729$.

2o. Ibid.

21. Ibid., $\ 733$.

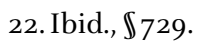

23. Hegel, Lectures on Aesthetics, 1036.

24. Hegel, Phenomenology, $\$ 733$.

25. Friedrich Schlegel, fragment from the Athenaeum no. 238, in "Lucinde" 
Not Yet

and the Fragments, trans. Peter Firchow (Minneapolis: University of Minnesota Press, 1971), 195.

26. Plato, Ion, trans. W. R. M. Lamb (Cambridge, MA: Harvard UP and London: Heinemann), 533b-534a.

27. Hans-Georg Gadamer, "Plato und die Dichter," in Gesammelte Werke, vol. 5 (Tübingen: Mohr, 1993), 189.

28. Ion, 534 c, e.

29. Friedrich Nietzsche, The Birth of Tragedy, trans. Douglas Smith (Oxford, New York: Oxford UP, 2000), 35.

30. For the following, cf. Christoph Menke, "The Dialectic of Aesthetics: The New Strife Between Philosophy and Art," in Aesthetic Experience, ed. Richard Shusterman and Adele Tomlin (Abingdon and New York: Routledge, 2008), 59-75.

31. Friedrich Schlegel, Critical Fragment [from the Lyceum] 108, in "Lucinde" and the Fragments, 156. 